\title{
A comparison of perioperative safety for breast augmentation in cis- vs. trans patients
}

\author{
Kyle S. Gabrick, Fouad Chouiari, Kitae E. Park, Omar Allam, Mohammed Ali Mozaffari, John A. Persing, \\ Michael Alperovich
}

Division of Plastic and Reconstructive Surgery, Yale University, New Haven, CT, USA

Contributions: (I) Conception and design: KS Gabrick, M Alperovich; (II) Administrative support: O Allam, KS Gabrick; (III) Provision of study materials or patients: F Chouiari, M Alperovich; (IV) Collection and assembly of data: F Chouiari, O Allam, KE Park, MA Mozaffari; (V) Data analysis and interpretation: O Allam, KE Park, F Chouiari, KS Gabrick; (VI) Manuscript writing: All authors; (VII) Final approval of manuscript: All authors.

Correspondence to: Michael Alperovich, MD, MSc. 330 Cedar Street, Third Floor, Boardman Building, New Haven, CT 06520, USA.

Email: michael.alperovich@yale.edu.

\begin{abstract}
Background: Gender-affirming surgery provides a psychosocial benefit to transgender women. However, increased medical complexity within the transgender population has limited access for some transgender women. This study compared patient population comorbidities and 30-day peri-operative safety following primary augmentation mammoplasty between cis- and transgender women.

Methods: Data were extracted from the National Surgical Quality Improvement Program (NSQIP) database between 2007 and 2016. Transgender patients were identified using ICD-9 \&10 codes for gender dysphoria. Categorical variables were compared using chi-squared and Fisher's exact tests while independent $t$-tests were used for continuous variables. Statistical significance was set at $\mathrm{P}<0.05$.

Results: There were 4,234 breast augmentations identified in cisgender women and 137 in transgender women. Transgender women had a higher frequency of ASA-II and ASA-III patients $(\mathrm{P}<0.001)$, diabetes $(\mathrm{P}<0.001)$, hypertension $(\mathrm{P}=0.006)$, and active smoking status $(\mathrm{P}<0.001)$. Despite the higher comorbidity burden and routine use of hormonal therapy, there were no significant differences between populations in major or minor peri-operative complication rates.

Conclusions: Top surgery improves quality of life in transgender women. Despite the more complex preoperative risk profile in the transgender population, there is no difference in peri-operative safety profiles. Plastic surgeons treating this patient population should consider more liberal surgical indications for reconstructive top surgery compared with cosmetic breast augmentation.
\end{abstract}

Keywords: Transgender; breast augmentation; outcomes; top surgery; gender transition

Submitted Apr 17, 2020. Accepted for publication Aug 14, 2020.

doi: 10.21037/atm-20-3355

View this article at: http://dx.doi.org/10.21037/atm-20-3355

\section{Introduction}

Extensive literature supports the significant role of hormonal therapy and gender-affirming surgery on the improvement of psychological functioning, sexual functioning, and overall quality of life in patients with gender dysphoria (1). Gender transition improves patients' ability to develop social and professional relationships thereby easing integration into society (2).

The 7th edition of the World Professional Association for Transgender Health's (WPATH) Standards of Care advocates for gender-affirming surgery as medically necessary to relieve psychosocial distress associated with gender dysphoria. Gender-affirming surgery has gained national momentum following the passage of the Affordable Care Act which banned discrimination on the basis of gender identity $(3,4)$. As a result, increasing numbers of patients are seeking care for gender dysphoria nationwide (5). Yet, the true healthcare needs of transgender individuals are 
Page 2 of 7

Table 1 Demographic characteristics of the study population

\begin{tabular}{lc}
\hline Characteristics & Value \\
\hline Number of patients (SD) & 4,645 \\
Race, $\mathrm{n}(\%)$ & $3,594(77.4)$ \\
White & $186(4.3)$ \\
Black & $128(2.9)$ \\
Asian & $737(15.9)$ \\
Other & \\
ASA Classification, $\mathrm{n}(\%)$ & $2,541(56.5)$ \\
No disturb & $1,878(41.8)$ \\
Mild disturb & $75(1.7)$ \\
Severe disturb & $2(0.0)$ \\
Life threat & $0(0.0)$ \\
Moribund & $35.8(10.7)$ \\
Age (years), mean (SD) & \\
\hline
\end{tabular}

not completely known and some healthcare providers may find themselves unprepared.

Chest reconstruction ("top surgery") is an important part of the gender transition process for transgender females (TF). Hormonal therapy alone often yields inadequate breast volume necessitating breast augmentation (6). Top Surgery improves psychosocial well-being, satisfaction with breasts, and sexual well-being on standardized patientreported outcome surveys such as the Breast-Q (7). These gains are evident as early as four months postoperatively and are sustained years following surgery (7).

When compared to the general population, TF are challenged with a higher prevalence of mental health illness (major depressive disorder, post-traumatic stress disorder, and suicide attempts), human immunodeficiency virus (HIV) seropositivity, and sexually transmitted infections (8-11). These factors have caused a social stigma which contributes to the disparities in healthcare utilization by transgender females (12). Due to these trends, surgeons should modify operative indications to reflect the reconstructive nature of top surgery when compared with aesthetic breast augmentation. The majority of outcomes research following top surgery has had low sample sizes (13-16). There has been scant investigation comparing peri-operative safety profiles between cis- and trans- gender females undergoing breast augmentation.

The chief aim of this study is to compare medical comorbidities and peri-operative safety profiles between cis and transgender women undergoing breast augmentation. We present the following article in accordance with the STROBE reporting checklist (available at http://dx.doi. org/10.21037/atm-20-3355).

\section{Methods}

The study was conducted in accordance with the Declaration of Helsinki (as revised in 2013). The study was conducted in approval of Yale Ethical guidelines; consent was waived as this is a de-identified public database.

\section{Exclusion criteria}

Data was extracted from the National Surgical Quality Improvement Program (NSQIP) database between 2007 and 2016. NSQIP collects outcomes from over 200 hospitals in the United States and includes over 200 variables including demographics, comorbidities, complications, and outcomes.

Cases of breast augmentation were isolated utilizing procedural CPT code 19325 "Breast Augmentation with a Prosthetic Implant." Gender-affirming surgery was isolated using gender identity disorder and gender dysphoria codes in ICD-9 (302.0, 302.50, 302.51, 302.52, 302.6, 302.76, $302.85,302.9$ ) and ICD10 (F64.0, F64.1, F64.2, F64.8, F64.9, F66.0, Z87.890). Cisgender patients with breast augmentation were identified by ICD9 (V50.1) and ICD10 (Z41.1) codes for elective surgery. Concurrent mastopexies were identified utilizing CPT code 19316, so they could be excluded from the final analysis.

\section{Statistical analysis}

Patient demographics were analyzed using basic frequency demographics. Results were subdivided and analyzed based on cis- or transgender. An analysis was carried out comparing demographics, comorbidities, surgical factors, and outcomes. Categorical variables were compared utilizing chi-squared and Fisher's exact tests whereas continuous variables were compared utilizing independent $t$-tests. Statistical significance was set at $\mathrm{P}<0.05$.

\section{Results}

Between 2007 and 2016, 4,234 breast augmentations in cisgender women and 137 chest reconstructions in transgender women were identified. Mean ages were similar between groups (35.8 vs. 36.7; $\mathrm{P}=0.355$ ) (Table 1). 
Cisgender patients were significantly more likely to identify as White $(83.2 \%$ vs. $51.8 \% ; \mathrm{P}<0.001)$ and less likely to be Black (3.9\% vs. $16.1 \%$; $\mathrm{P}<0.001)$. Transgender females had a higher prevalence of diabetes $(2.9 \% v s$. $0.9 \% ; \mathrm{P}<0.001)$, current smoking status $(30.8 \%$ vs. $13.5 \%$; $\mathrm{P}<0.001)$, and hypertension requiring medication $(8.2 \%$ vs. $3.8 \% ; \mathrm{P}=0.006)$. Further, transgender women had significantly more women who were classified as ASA II (60.3\% vs. $31.8 \% ; \mathrm{P}<0.001)$ and ASA III $(10.3 \%$ vs. $1.7 \%$; $\mathrm{P}<0.001)$ with proportionally fewer as ASA I $(28.8 \%$ vs. $56.5 \% ; \mathrm{P}<0.001)$. While there were no significant differences in operative duration, transgender women had a significantly longer length of hospital stay ( 0.6 vs. 0.1 days; $\mathrm{P}=0.01$ ) (Table 2).

Cisgender women had higher rates of concurrent mastopexy ( $7.1 \%$ vs. $1.4 \% ; \mathrm{P}=0.007)$. Cases of augmentation performed with concurrent mastopexy were excluded from the outcomes analysis.

Breast augmentation had comparable outcomes regardless of gender orientation across all peri-operative complications. There were no differences in minor complications such as surgical site infections $(\mathrm{P}=0.999)$, DVT/PE ( $\mathrm{P}=0.999)$, and bleeding $(\mathrm{P}=0.0999)$. Thirtyday mortality $(\mathrm{P}=0.999)$, prolonged hospital admission $(\mathrm{P}=0.999)$, readmission $(\mathrm{P}=0.260)$, reoperation $(\mathrm{P}=0.324)$ and deep wound dehiscence $(\mathrm{P}=0.999)$ rates were similar between cohorts (Table 3).

\section{Discussion}

This study compared patient demographics, medical comorbidities, and peri-operative safety profiles between cis- and transgender women undergoing primary breast augmentation utilizing data from the National Surgical Quality Improvement Program. To date, this is the first study comparing comorbidities and peri-operative safety profiles stratified by this type of comparison.

These data confirm that primary top surgery can be performed safely in TF despite heightened medical comorbidities and surgical risk profiles. The transgender cohort had longer admissions on average, which may be a result of the multi-disciplinary nature of gender transition. Despite the heightened psychosocial and medical complexity of transgender women, peri-operative safety profiles are similar to the healthier cisgender cohort with elective indications (13-17).

The higher proportion of ASA II and III patients in the transgender group would typically be associated with an overall poorer baseline health and are an independent predictor of morbidity and wound complications following breast surgery $(17,18)$. Despite the higher surgical risk posed by ASA scores, transgender women did not show any higher rates of 30-day peri-operative complications. Previous studies have shown that diabetes and hypertension-both significantly more prevalent in the transgender cohort-have odds ratios for developing postoperative complications of 3.1 and 2.4, respectively (19). In our study, these comorbidities did not impact safety profiles among transgender women in the first thirty days. Finally, transgender women had a much higher prevalence of active smoking status when compared to cisgender women (19-21). Given the benefits of surgery to patient satisfaction and psychological well-being with adequate peri-operative safety profiles surgeons should adopt more liberal operative indications for reconstructive top surgery than cosmetic breast augmentation.

As per WPATH guidelines, patients undergoing surgery usually receive hormonal therapy to maximize natural breast development $(22,23)$. Exogenous estrogens place patients at increased risk for thromboembolic events, cardiovascular, and cerebrovascular complications in the post-operative period $(22,24,25)$. These risks are greater in transgender women when compared to cisgender patients 27 and are further increased in the presence of diabetes, hypertension, and active smoking status (26-30). A Dutch study found the incidence of thrombotic events was 20 times greater in the first two years following the initiation of estrogen replacement therapy (31). Despite this heightened risk, no significant differences were observed in thromboembolic events or cardiac arrest. The recommendations regarding continuing hormonal therapy in the perioperative period are controversial with some anesthesia providers recommending cessation of hormone replacement therapy 2-4 weeks prior to surgery (32). However, the decision to stop hormone therapy varies widely by surgeon (33). While this analysis suggests that patients did not have a higher incidence of thromboembolic events, whether these patients halted hormone therapy prior to surgery was unavailable.

Concurrent augmentation-mastopexies were more prevalent in cisgender women than transgender. Given that the mean age of both cohorts was in the mid-thirties, cisgender breasts were exposed to longer periods of breast ptosis, cyclic hormones, and weight fluctuations which could account for greater rates of ptosis and mastopexy. Further, transgender females undergo breast augmentation for inadequate breast size and, often, associated skin (4).

This study was not intended and does not address 
Table 2 Medical comorbidities stratified by cis and trans gender patients

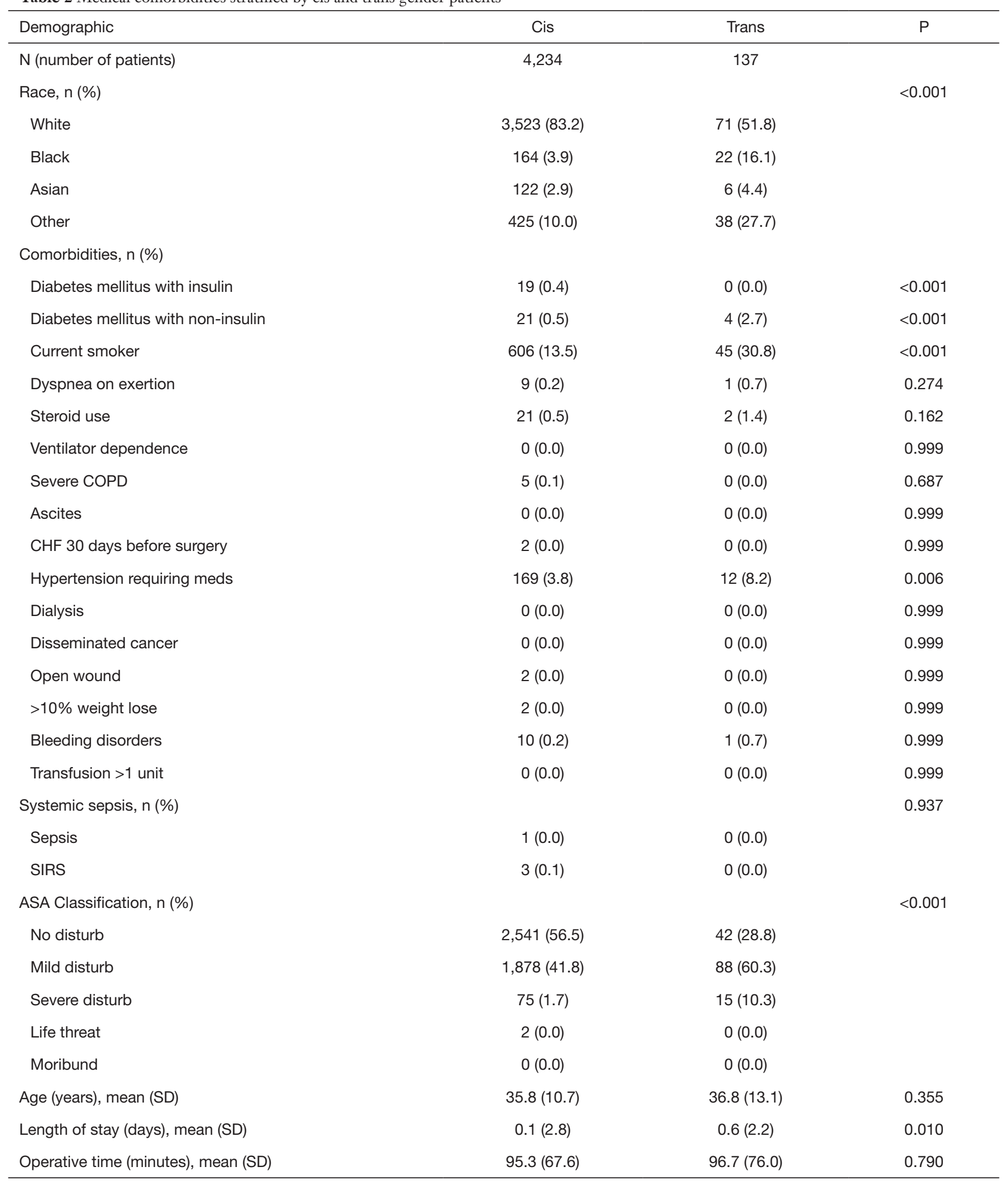


Table 3 Surgical complications stratified by cis and trans gender patients

\begin{tabular}{|c|c|c|c|}
\hline Complication & Cis, n (\%) & Trans, n (\%) & $\mathrm{P}$ \\
\hline \multicolumn{4}{|l|}{ Complications } \\
\hline In hospital $>30$ days & $0(0.0)$ & $0(0.0)$ & 0.999 \\
\hline Death in 30 days & $0(0.0)$ & $0(0.0)$ & 0.999 \\
\hline Superficial incisional SSI & $9(0.2)$ & $0(0.0)$ & 0.999 \\
\hline Deep incisional SSI & $3(0.1)$ & $0(0.0)$ & 0.999 \\
\hline Organ SSI & $4(0.1)$ & $0(0.0)$ & 0.999 \\
\hline Deep wound dehiscence & $0(0.0)$ & $0(0.0)$ & 0.999 \\
\hline Pneumonia & $0(0.0)$ & $0(0.0)$ & 0.999 \\
\hline Unplanned intubation & $0(0.0)$ & $0(0.0)$ & 0.999 \\
\hline Pulmonary embolism & $3(0.1)$ & $0(0.0)$ & 0.999 \\
\hline DVT/thrombophlebitis & $2(0.0)$ & $0(0.0)$ & 0.999 \\
\hline Post-op ventilator & $0(0.0)$ & $0(0.0)$ & 0.999 \\
\hline Renal insufficiency & $0(0.0)$ & $0(0.0)$ & 0.999 \\
\hline Renal failure & $0(0.0)$ & $0(0.0)$ & 0.999 \\
\hline Urinary tract infection & $8(0.2)$ & $0(0.0)$ & 0.999 \\
\hline CVA/stroke & $0(0.0)$ & $0(0.0)$ & 0.999 \\
\hline Cardiac arrest & $0(0.0)$ & $0(0.0)$ & 0.999 \\
\hline Bleeding & $0(0.0)$ & $0(0.0)$ & 0.999 \\
\hline Sepsis & $0(0.0)$ & $0(0.0)$ & 0.999 \\
\hline Septic shock & $0(0.0)$ & $0(0.0)$ & 0.999 \\
\hline Readmission & $21(0.5)$ & $2(1.4)$ & 0.260 \\
\hline Reoperation & $49(1.2)$ & $3(2.1)$ & 0.324 \\
\hline
\end{tabular}

long-term outcomes such as implant revision rates, capsular contracture, breast asymmetry, or breast pain. It primarily addresses short term perioperative outcomes when applying less restrictive surgical indications in the transgender population. Limitations of this study include the heterogeneous cohorts. Identification of transgender patients was based on ICD9/ICD10 codes associated with gender dysphoria. Details regarding anatomic plane of implant placement and type of implant unavailable. This analysis remains the first comparison in the surgical literature of comorbidities and outcomes of breast augmentation stratified by cis and transgender communities.

\section{Conclusions}

Previously reported national sample data has demonstrated an increasing number of transgender patients seeking gender-affirming therapy (5). Top surgery has the potential to significantly improve and maintain quality of life (25). Despite increased preoperative comorbidities, transgender women undergoing chest reconstruction have similar perioperative safety profiles to cisgender women undergoing cosmetic breast augmentation.

\section{Acknowledgments}

Funding: None.

\section{Footnote}

Provenance and Peer Review: This article was commissioned by the Guest Editors (Dr. Oscar J. Manrique, Dr. John A. Persing, and Dr. Xiaona Lu) for the series "Transgender Surgery" published in Annals of Translational Medicine. The article was sent for external peer review organized by the Guest Editors and the editorial office.

Reporting Checklist: The authors have completed the STROBE reporting checklist. Available at http://dx.doi. org/10.21037/atm-20-3355

Conflicts of Interest: All authors have completed the ICMJE uniform disclosure form (available at http://dx.doi. org/10.21037/atm-20-3355). The series "Transgender Surgery" was commissioned by the editorial office without any funding or sponsorship. JP served as the unpaid Guest Editor of the series. The authors have no other conflicts of interest to declare.

Ethical Statement: The authors are accountable for all aspects of the work in ensuring that questions related to the accuracy or integrity of any part of the work are appropriately investigated and resolved. The study was conducted in accordance with the Declaration of Helsinki (as revised in 2013). The study was conducted in approval of Yale Ethical guidelines; consent was waived as this is a deidentified public database. All available data can be obtained by contacting the corresponding author or the American College of Surgeons, NSQIP committee.

Open Access Statement: This is an Open Access article distributed in accordance with the Creative Commons Attribution-NonCommercial-NoDerivs 4.0 International License (CC BY-NC-ND 4.0), which permits the non- 
commercial replication and distribution of the article with the strict proviso that no changes or edits are made and the original work is properly cited (including links to both the formal publication through the relevant DOI and the license). See: https://creativecommons.org/licenses/by-nc-nd/4.0/.

\section{References}

1. Murad MH, Elamin MB, Garcia MZ, et al. Hormonal therapy and sex reassignment: a systematic review and meta-analysis of quality of life and psychosocial outcomes. Clin Endocrinol (Oxf) 2010;72:214-31.

2. Cardoso da Silva D, Schwarz K, Fontanari AM, et al. WHOQOL-100 Before and After Sex Reassignment Surgery in Brazilian Male-to-Female Transsexual Individuals. J Sex Med 2016;13:988-93.

3. Padula WV, Heru S, Campbell JD. Societal Implications of Health Insurance Coverage for Medically Necessary Services in the U.S. Transgender Population: A CostEffectiveness Analysis. J Gen Intern Med 2016;31:394-401.

4. Baker KE. The Future of Transgender Coverage. N Engl J Med 2017;376:1801-4.

5. Canner JK, Harfouch O, Kodadek LM, et al. Temporal Trends in Gender-Affirming Surgery Among Transgender Patients in the United States. JAMA Surg 2018;153:609-16.

6. Orentreich N, Durr NP. Proceedings: Mammogenesis in transsexuals. J Invest Dermatol 1974;63:142-6.

7. Weigert R, Frison E, Sessiecq Q, et al. Patient satisfaction with breasts and psychosocial, sexual, and physical wellbeing after breast augmentation in male-to-female transsexuals. Plast Reconstr Surg 2013;132:1421-9.

8. Bockting WO, Miner MH, Swinburne Romine RE, et al. Stigma, mental health, and resilience in an online sample of the US transgender population. Am J Public Health 2013;103:943-51.

9. Operario D, Soma T, Underhill K. Sex work and HIV status among transgender women: systematic review and metaanalysis. J Acquir Immune Defic Syndr 2008;48:97-103.

10. Clements-Nolle K, Marx R, Katz M. Attempted suicide among transgender persons: The influence of genderbased discrimination and victimization. J Homosex 2006;51:53-69.

11. Dhejne C, Lichtenstein P, Boman M, et al. Longterm follow-up of transsexual persons undergoing sex reassignment surgery: cohort study in Sweden. PLoS One 2011;6:e16885.

12. Brown GR, Jones KT. Mental Health and Medical Health Disparities in 5135 Transgender Veterans Receiving
Healthcare in the Veterans Health Administration: A Case-Control Study. LGBT Health 2016;3:122-31.

13. Ratnam SS, Lim SM. Augmentation mammoplasty for the male transsexual. Singapore Med J 1982;23:107-9.

14. Kanhai RC, Hage JJ, Asscheman H, et al. Augmentation mammaplasty in male-to-female transsexuals. Plast Reconstr Surg 1999;104:542-9; discussion 550-1.

15. Kanhai RC, Hage JJ, Karim RB, et al. Exceptional presenting conditions and outcome of augmentation mammaplasty in male-to-female transsexuals. Ann Plast Surg 1999;43;476-83.

16. Kanhai RC, Hage JJ, Mulder JW. Long-term outcome of augmentation mammaplasty in male-to-female transsexuals: A questionnaire survey of 107 patients. Br J Plast Surg 2000;53:209-11.

17. Massenburg BB, Sanati-Mehrizy P, Ingargiola MJ, et al. Flap failure and wound complications in autologous breast reconstruction: a national perspective. Aesthetic Plast Surg 2015;39:902-9.

18. Fischer JP, Nelson JA, Au A, et al. Complications and morbidity following breast reconstruction-a review of 16,063 cases from the 2005-2010 NSQIP datasets. J Plast Surg Hand Surg 2014;48:104-14.

19. Hanwright PJ, Hirsch EM, Seth AK, et al. A multiinstitutional perspective of complication rates for elective nonreconstructive breast surgery: an analysis of NSQIP data from 2006 to 2010. Aesthet Surg J 2013;33:378-86.

20. Singh N, Picha GJ, Murphy DK. Natrelle silicone breast implant follow-up study: demographics, lifestyle, and surgical characteristics of more than 50,000 augmentation subjects. Plast Reconstr Surg 2016;137:70.

21. Alderman A, Pusic A, Murphy DK. Prospective analysis of primary breast augmentation on body image using the BREAST-Q: results from a nationwide study. Plast Reconstr Surg 2016;137:954e.

22. Rosendale N, Goldman S, Ortiz GM, et al. Acute clinical care for transgender patients: a review. JAMA Intern Med 2018;178:1535-43.

23. Coleman E, Bockting W, Botzer $M$, et al. Standards of care for the health of transsexual, transgender, and gender-nonconforming people, version 7. Intern J Trans 2012;13:165-232.

24. Asscheman H, T'Sjoen G, Lemaire A, et al. Venous thrombo-embolism as a complication of cross-sex hormone treatment of male-to-female transsexual subjects: a review. Andrologia 2014;46:791-5.

25. Wierckx K, Elaut E, Declercq E, et al. Prevalence of cardiovascular disease and cancer during cross-sex 
hormone therapy in a large cohort of trans persons: a casecontrol study. Eur J Endocrinol 2013;169:471-8.

26. Getahun D, Nash R, Flanders WD, et al. Cross-sex hormones and acute cardiovascular events in transgender persons: a cohort study. Annals of internal medicine 2018;169:205-13.

27. Arnold JD, Sarkodie EP, Coleman ME, et al. Incidence of venous thromboembolism in transgender women receiving oral estradiol. Ann Intern Med 2016;13:1773-7.

28. Goldhaber SZ. Risk factors for venous thromboembolism. J Am Coll Cardiol 2010;56:1-7.

29. Micieli E, Dentali F, Giola M, et al. Venous and arterial thrombosis in patients with HIV infection. Blood Coagul Fibrinolysis 2007;18:259-63.

Cite this article as: Gabrick KS, Chouiari F, Park KE, Allam O, Mozaffari MA, Persing JA, Alperovich M. A comparison of perioperative safety for breast augmentation in cis- $v s$. trans patients. Ann Transl Med 2021;9(7):601. doi: 10.21037/atm-203355
30. Ageno W, Becattini C, Brighton T, et al. Cardiovascular risk factors and venous thromboembolism. Circulation 2008;117:93-102.

31. Seal LJ. A review of the physical and metabolic effects of cross-sex hormonal therapy in the treatment of gender dysphoria. Ann Clin Biochem 2016;53:10-20.

32. Berli JU, Knudson G, Fraser L, et al. What surgeons need to know about gender confirmation surgery when providing care for transgender individuals: a review. JAMA Surg 2017;152:394-400.

33. Lawrence AA. Patient-reported complications and functional outcomes of male-to-female sex reassignment surgery. Arch Sex Behav 2006;35:717-27. 